\title{
Involvement of JunD in Transcriptional Activation of the Orphan Receptor Gene nur77 by Nerve Growth Factor and Membrane Depolarization in PC12 Cells
}

\author{
JEONG KYO YOON† AND LESTER F. LAU* \\ Department of Genetics, University of Illinois College of Medicine, Chicago, Illinois 60612
}

Received 14 February 1994/Returned for modification 23 March 1994/Accepted 9 September 1994

\begin{abstract}
nur77, an immediate-early gene that encodes an orphan nuclear receptor, is rapidly and transiently induced by nerve growth factor (NGF) stimulation or membrane depolarization in the rat pheochromocytoma-derived cell line PC12. The Nur77 protein can act as a potent transcription activator and may function to regulate the expression of downstream genes in response to extracellular stimuli. We show here that activation of nur77 by NGF treatment and membrane depolarization is signalled through distinct pathways. These distinct signals appear to converge on the same transcription factors acting on the same promoter elements. We show that nur77 activation by both processes requires two cis-acting AP1-like elements, NAP1 and NAP2, which contain the core sequence TGCGTCA centered at 67 and 38 nucleotides upstream of the transcription start site. The NAP elements can confer inducibility by NGF and membrane depolarization on an otherwise unresponsive heterologous promoter. We identified JunD as a key mediator of nur77 activation by reason of the following observations. (i) JunD, but not CREB or other members of the Fos/Jun family, is a component of NAP binding activity in PC12 cell nuclear extracts. (ii) JunD, but not other Fos/Jun family members, specifically transactivates the nur77 promoter through the NAP elements (iii) A dominant-negative mutant of JunD effectively abolishes the activation of nur77 by either NGF treatment or membrane depolarization. These data draw a contrast between the regulation of nur77 with that of $c-f o s$, in which the sequence requirements for activation by NGF treatment and membrane depolarization appear separable, and CREB appears to play a role in activation by both NGF and membrane depolarization.
\end{abstract}

The primary genetic response in mammalian cells exposed to a variety of extracellular signalling agents is the rapid and transient induction of a set of genes, called immediate-early genes $(28,36)$. The induction of these genes does not require de novo protein synthesis and is likely to be mediated by the posttranslational modification of existing transcription factors. Many immediate-early genes are known to encode transcription factors thought to regulate the expression of downstream genes, which may in turn act as effectors of the cellular responses to the extracellular stimuli.

A particularly interesting cell culture system for studying transcriptional activation of immediate-early genes is the rat pheochromocytoma-derived cell line PC12, since it can undergo disparate cellular processes depending on the stimulating agents $(15,21,22)$. Nerve growth factor (NGF) stimulates PC12 cells to differentiate into sympathetic neuron-like cells, whereas epidermal growth factor is mitogenic without inducing differentiation. In addition, PC12 cells have excitable membranes that could be depolarized by specific neurotransmitters or elevated levels of extracellular $\mathrm{KCl}(13,20,22)$. Thus, PC12 cells provide a model for studying gene regulation in response to agents that induce either differentiation or proliferation or to stimuli that mimic neurotransmission.

Among immediate-early genes, the proto-oncogene c-fos has been the most extensively studied with regard to its transcriptional regulation $(2,16,47,54,60)$. The activation of $c$-fos in PC12 cells by NGF, epidermal growth factor, or tetradecanoyl

\footnotetext{
* Corresponding author. Mailing address: Department of Genetics, University of Illinois College of Medicine, 808 South Wood St., Chicago, IL 60612. Phone: (312) 996-6978. Fax: (312) 996-7034.

$\dagger$ Present address: Division of Biology, California Institute of Technology, Pasadena, CA 91125.
}

phorbol acetate (TPA) is mediated primarily through the serum response element $(53,63)$. The c-fos serum response element contains a CArG box (41), which binds to a $67-\mathrm{kDa}$ serum response factor (59), and an adjacent binding site for a protein of the Ets family, most likely Elk-1 or SAP-1 $(7,29,38)$. In contrast, transcriptional activation of c-fos by membrane depolarization, $\mathrm{Ca}^{2+}$ influx, and elevation of cyclic AMP (cAMP) is mediated through a cAMP response element (CRE)-like sequence that binds CREB in vitro $(14,53,55)$. The transcription efficacy of CREB is known to be modulated by phosphorylation on serine 133, either by the cAMP-dependent protein kinase A (PKA) $(19,71)$ or by the $\mathrm{Ca}^{2+}$ calmodulin-dependent protein kinase II (CaMII kinase) ( 8 , 56). These results suggest that membrane depolarization might activate c-fos by activating CREB via signalling through cAMP- or $\mathrm{Ca}^{2+}$-dependent kinases. In addition, full induction of c-fos by NGF also requires intact CREs and involves the activation of CREB through a Ras-dependent protein kinase (17).

To expand our knowledge of the mechanisms regulating immediate-early gene activation, we have studied the transcriptional regulation of the orphan nuclear receptor gene nur77 (72). nur77 (also known as N10 and NGFI-B) $(26,40,51)$ is rapidly and transiently induced by serum growth factors in fibroblasts $(26,66)$ and by NGF stimulation and membrane depolarization in PC12 cells with kinetics similar to those of c-fos $(3,40)$. The nur77-encoded protein is a member of the steroid hormone receptor superfamily $(26,40)$ and has been shown to act as a potent transcriptional activator through interactions with DNA at sequence-specific sites $(9,10,67,68)$. Studies of the expression of nur77 suggest that Nur77 may play important roles in the central and peripheral nervous systems and in steroidogenic organs, including the adrenal gland (11, 
linearized with appropriate restriction enzymes and used as templates for in vitro synthesis of RNA with either T7 or SP6 RNA polymerase. In vitro translation was performed in the rabbit reticulocyte lysates programmed with the RNAs as directed by the manufacturer (Promega) in either the absence or the presence of $\left[{ }^{35} \mathrm{~S}\right]$ methionine.

Electrophoretic mobility shift assay (EMSA). Nuclear lysate or in vitro-synthesized proteins were incubated with $0.5 \mathrm{ng}$ of the appropriate ${ }^{32} \mathrm{P}$-labeled oligonucleotides in $12 \mathrm{mM}$ HEPES-KOH ( $\mathrm{pH}$ 7.9)-60 mM NaCl-1 mM $\mathrm{MgCl}_{2}-1 \mathrm{mM}$ dithiothreitol-12\% glycerol in the presence of $1 \mu \mathrm{g}$ of poly(dI$\mathrm{dC}$ ) and $1 \mu \mathrm{g}$ of salmon sperm DNA for $30 \mathrm{~min}$ at room temperature. For NAP2, the oligonucleotide 5'-TCGAGC TCTCCATGCGTCACGGAGCGC and the corresponding complementary strand were used. For AP1 binding assays, the oligonucleotide 5'-GATCCATGACTCAGAGGAAAAC ATAC and the corresponding complementary strand were used. For competition, a 20 - or 100 -fold molar excess of cold NAP2, NAP1 (5'-CTAGACGTGTGCGTCAGTGGT), M5 (5'-GGCGCCACTTCTGCACACGGC), M7 (5'-TCTCCAT GCAGAACGGAGCGC), AP1, CRE (5'-CTAGATTGCCT GACGTCAGAGAGT), or c-fos CaRE (5'-CTAGAGCCCG TGACGTTTACACTCAT) oligonucleotides were added with the corresponding complementary strand to the binding reaction mixture, which was then incubated on ice for $20 \mathrm{~min}$ prior to the addition of the ${ }^{32} \mathrm{P}$-labeled probe. Anti-JunD (kindly provided by Rodrigo Bravo, Bristol-Myers Squibb, Princeton, N.J.), anti-c-Fos, anti-c-Jun, anti-JunB, anti-CREB (Santa Cruz Biotechnology, Santa Cruz, Calif.), or anti-Nur77 (25) antibodies were added directly to the binding reaction mixture, which was then incubated on ice for $20 \mathrm{~min}$ prior to the addition of probe. Protein-DNA complexes were separated on a $4 \%$ polyacrylamide gel (1:80, bisacrylamide-acrylamide) with $0.25 \times$ Tris-borate-EDTA buffer and visualized by autoradiography.

Immunoprecipitation of Fos-JunD heterodimers. Equal amounts of ${ }^{35}$ S-labeled, in vitro-translated Fos, JunD, or JunD mut proteins were mixed and allowed to form complexes at room temperature for $30 \mathrm{~min}$. The protein mixtures were incubated with either anti-Fos antibodies (Oncogene Science) or anti-JunD antibodies for $1 \mathrm{~h}$ on ice and then incubated with protein A-Sepharose CL-4B (Pharmacia) for $1 \mathrm{~h}$ with constant shaking at $4^{\circ} \mathrm{C}$. The immunoprecipitates were collected by centrifugation and washed with a buffer (10 mM Tris [pH 7.5], $150 \mathrm{mM} \mathrm{NaCl}, 2 \mathrm{mM}$ EDTA, and $0.2 \%$ Nonidet P-40) three times and with $10 \mathrm{mM}$ Tris $(\mathrm{pH} 7.5)$ once. The immunoprecipitated proteins were resolved by SDS-10\% polyacrylamide gel electrophoresis (PAGE) followed by fluorography.

\section{RESULTS}

Distinct signalling pathways mediate induction of nur77 by NGF and KCl. In PC12 cells, nur77 is rapidly induced by stimulation with NGF and by membrane depolarization (3, $40)$. In addition, nur 77 can be induced by other agents such as TPA or forskolin $(28,36)$, suggesting that nur77 induction may be mediated through the activation of protein kinases. To gain insight into the signal transduction pathways for nur77 activation, we have examined the possible roles of different protein kinases.

That TPA induces nur77 suggests that protein kinase $\mathrm{C}$ (PKC) is able to mediate nur77 activation. To determine whether PKC activity is obligatory for nur77 induction, we treated PC12 cells with TPA for $24 \mathrm{~h}$ to down-regulate PKC activity (48). The induction of nur77 in response to NGF or $\mathrm{KCl}$ in TPA-treated cells was compared with that in untreated
A

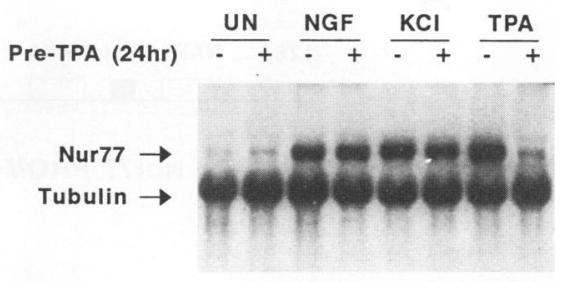

B

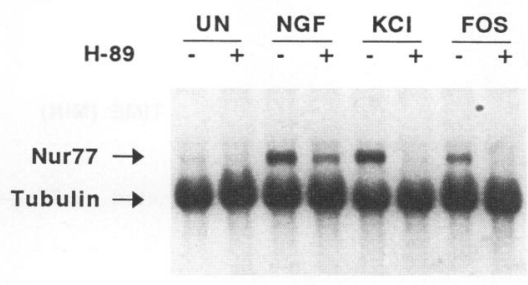

C

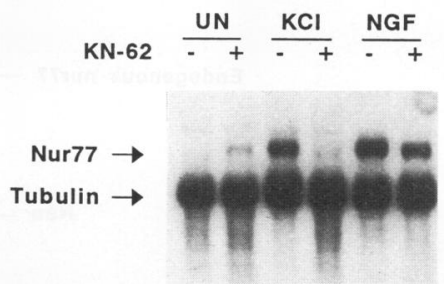

FIG. 1. NGF and $\mathrm{KCl}$ induce nur77 through distinct signalling pathways. PC12 cells were harvested either without stimulation (UN) or after $1 \mathrm{~h}$ of stimulation with NGF, TPA, $\mathrm{KCl}$, or forskolin (FOS). Samples $(10 \mu \mathrm{g})$ of total RNA from these cells were analyzed by RNA blot hybridization with a ${ }^{32} \mathrm{P}$-labeled nur77 cDNA probe; a tubulin probe was also added in the same hybridization mixture to normalize the quantity and control for the quality of RNA. (A) PKC downregulation. Cells were stimulated without TPA treatment (-) or were pretreated with TPA for $24 \mathrm{~h}(+)$ prior to stimulation with the indicated agents. (B and C) Effects of the specific kinase inhibitors on nur77 expression. Cells were stimulated in the absence $(-)$ or in the presence (+) of the PKA inhibitor H-89 (B) or of the CaMII kinase inhibitor $\mathrm{KN}-62$ (C). $\mathrm{H}-89$ and $\mathrm{KN}-62$ were added to the culture medium to 20 and $10 \mu \mathrm{M}$, respectively, 30 min prior to stimulation with the indicated agents.

cells (Fig. 1A). nur77 induction by TPA was observed after $1 \mathrm{~h}$ in naive cells but not in TPA-pretreated cells, demonstrating that PKC activity was effectively down-regulated. Treatment with $\mathrm{NGF}$ and $\mathrm{KCl}$, however, resulted in similar levels of nur77 induction in TPA-pretreated cells and untreated cells (Fig. 1A), indicating that induction of nur77 by $\mathrm{NGF}$ and $\mathrm{KCl}$ can occur through pathways that do not involve phorbol estersensitive PKC.

nur77 is activated by treatment with forskolin, suggesting that the cAMP-dependent PKA may be involved in its activation (Fig. 1B). To test whether PKA is required for activation of nur 77 by NGF or $\mathrm{KCl}$, we treated cells with the known PKA inhibitor $\mathrm{H}-89$ (4) for 30 min prior to NGF or $\mathrm{KCl}$ stimulation (Fig. 1B). The activation of nur77 by NGF was partially inhibited in the presence of $\mathrm{H}-89$. In contrast, nur77 activation by either $\mathrm{KCl}$ or forskolin was completely blocked by the inhibitor. These results indicate that PKA may mediate one 
A
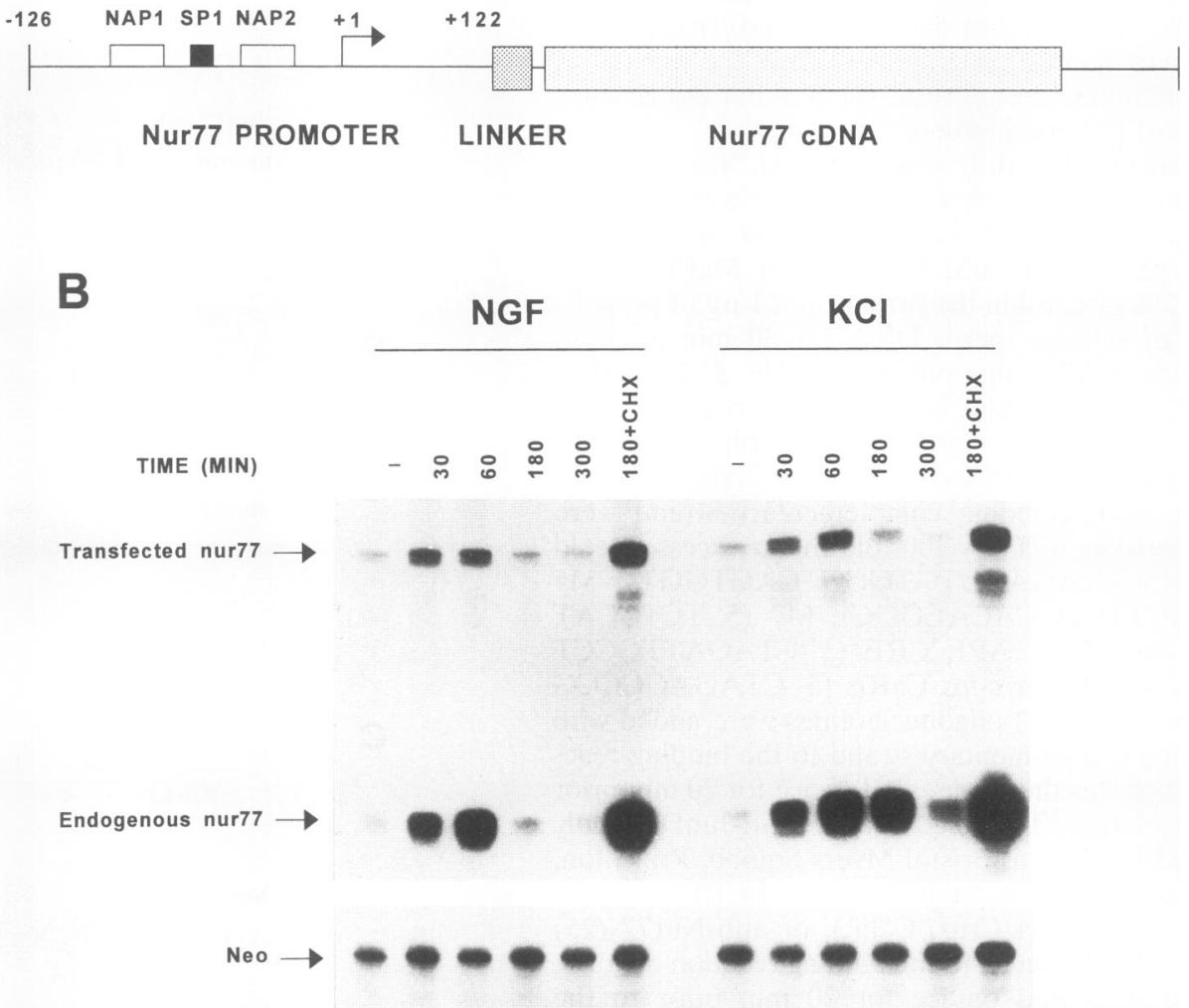

FIG. 2. Kinetics of expression of transfected nur77 minigene. (A) Structure of the 126/77TR minigene (72). A total of 126 bp of nur77 5 '-flanking sequence was fused to the nur77 cDNA, which is interrupted by an 11-bp linker. (B) Expression of the transfected minigene. PC12 cells were transfected with $26 \mu \mathrm{g}$ of the 126/77TR minigene plasmid and $14 \mu \mathrm{g}$ of $\mathrm{pSV}_{2}$ neo plasmid as a reference by electroporation. Cells were stimulated with NGF or $\mathrm{KCl}$ for the indicated durations in the absence or presence of cycloheximide (CHX), and total cellular RNA was analyzed by an S1 nuclease protection assay. Protected products corresponding to transcripts from the transfected minigene, the endogenous nur 77 , and the neo gene are indicated.

component of nur77 activation by NGF but plays a major role in the activation of nur77 by $\mathrm{KCl}$.

Since the main effect of $\mathrm{KCl}$ treatment in $\mathrm{PC} 12$ cells is the increase of intracellular $\mathrm{Ca}^{2+}$ levels through the influx of extracellular $\mathrm{Ca}^{2+}(13,20,22)$, we tested whether CaMII kinase can mediate nur 77 activation by treating cells with the CaMII kinase-specific inhibitor $\mathrm{KN}-62$ (58) before NGF or $\mathrm{KCl}$ stimulation (Fig. 1C). The activation of nur77 by $\mathrm{KCl}$ was completely inhibited by $\mathrm{KN}-62$, whereas activation by NGF was not significantly affected. Therefore, CaMII kinase may be involved in the activation of nur 77 by $\mathrm{KCl}$ but not in activation by NGF. Although pharmacological approaches in the analysis of signalling pathways have limitations with regard to the specificity of the compounds used, our results show that induction by $\mathrm{NGF}$ and $\mathrm{KCl}$ is differentially affected by the same compounds. Taken together, these results show that nur77 activation by NGF or $\mathrm{KCl}$ is mediated through distinct and separable pathways and suggest that PKA and CaMII kinase may play major roles in the activation by membrane depolarization.

Accurate transcription kinetics of transfected nur77 minigenes. The kinetics of nur77 expression in $\mathrm{NGF}$ - or $\mathrm{KCl}-$ stimulated PC12 cells are rapid and transient (3), suggesting that transcriptional repression, or the loss of activation, occurs soon after the onset of transcriptional activation upon stimulation. We previously reported that a nur77 minigene contain- ing $1.1 \mathrm{~kb}$ of sequences upstream of the transcription start site is expressed with kinetics identical to those of the endogenous nur77 gene (72). Here, we show that the sequence information that specifies these expression kinetics is encoded within the first $126 \mathrm{bp}$ upstream of the transcription start site, contained in the 126/77TR minigene (Fig. 2). The 126/77TR minigene was transfected into PC12 cells, and the time course of expression of the transfected gene was analyzed (Fig. 2B). As described previously, the endogenous levels of nur77 mRNA induced by NGF reached a peak by $1 \mathrm{~h}$ and declined to the unstimulated level by $3 \mathrm{~h}$, whereas the expression induced by $\mathrm{KCl}$ exhibited slightly more prolonged kinetics (72). The transfected nur77 minigene is expressed with kinetics virtually identical to those of the endogenous nur77 and was superinduced by the protein synthesis inhibitor cycloheximide.

NAP1 and NAP2 are the major cis-acting elements for NGF and $\mathrm{KCl}$ stimulation. We previously reported that a DNA fragment containing nt -90 to -22 of the nur 77 promoter can confer inducibility by $\mathrm{NGF}$ or $\mathrm{KCl}$ on a heterologous promoter (72). Within this DNA fragment, there are two AP1-like sequences (NAP1 and NAP2), two overlapping SP1 binding sites, and a Zif268 binding site (5) (Fig. 3A). To determine more precisely the promoter sequences required for activation of nur77, we created a series of base substitution mutations in the context of the 126/77TR minigene (Fig. 3A). The promoter activities of these mutant minigenes were analyzed by $\mathrm{S} 1$ 
A
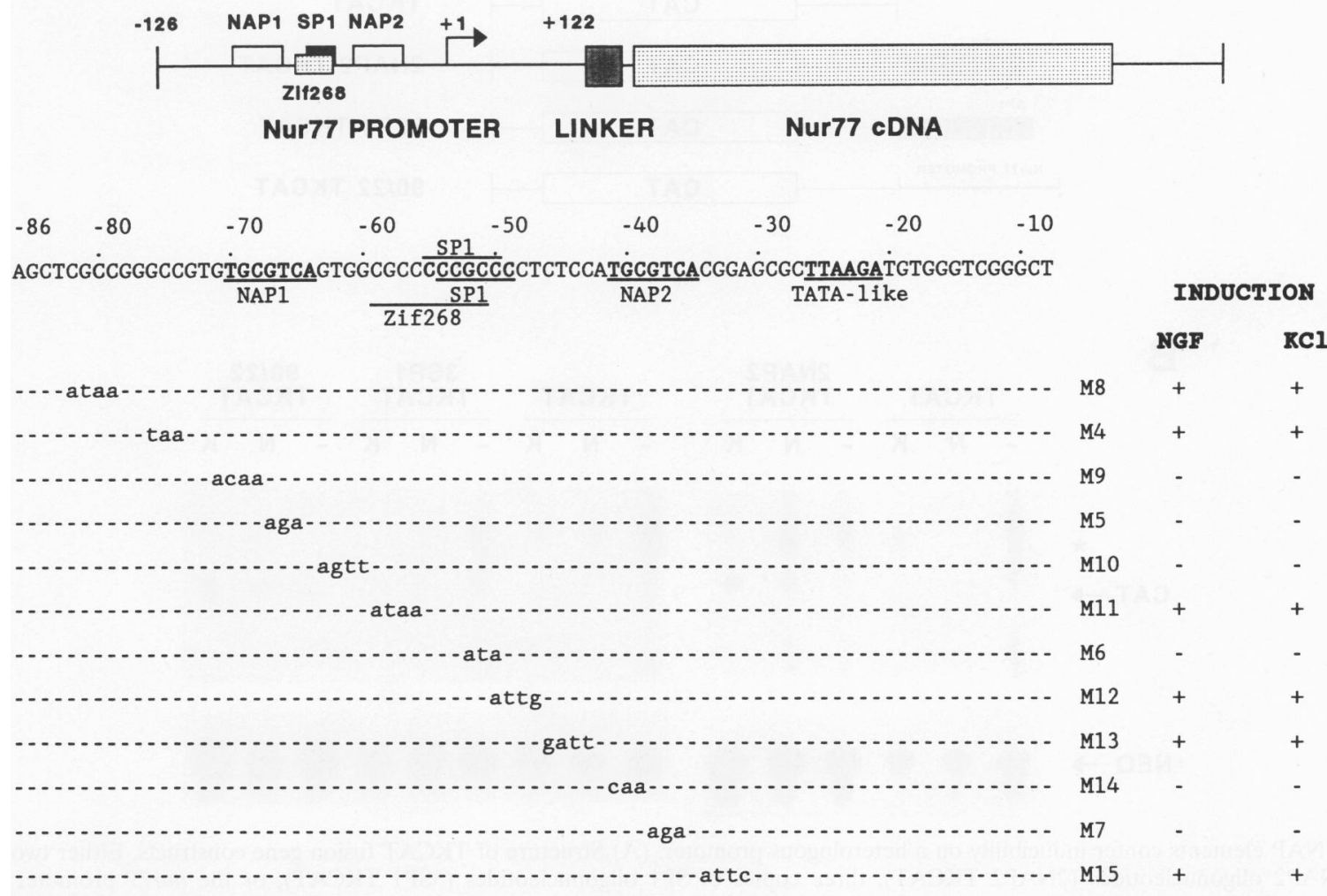

B

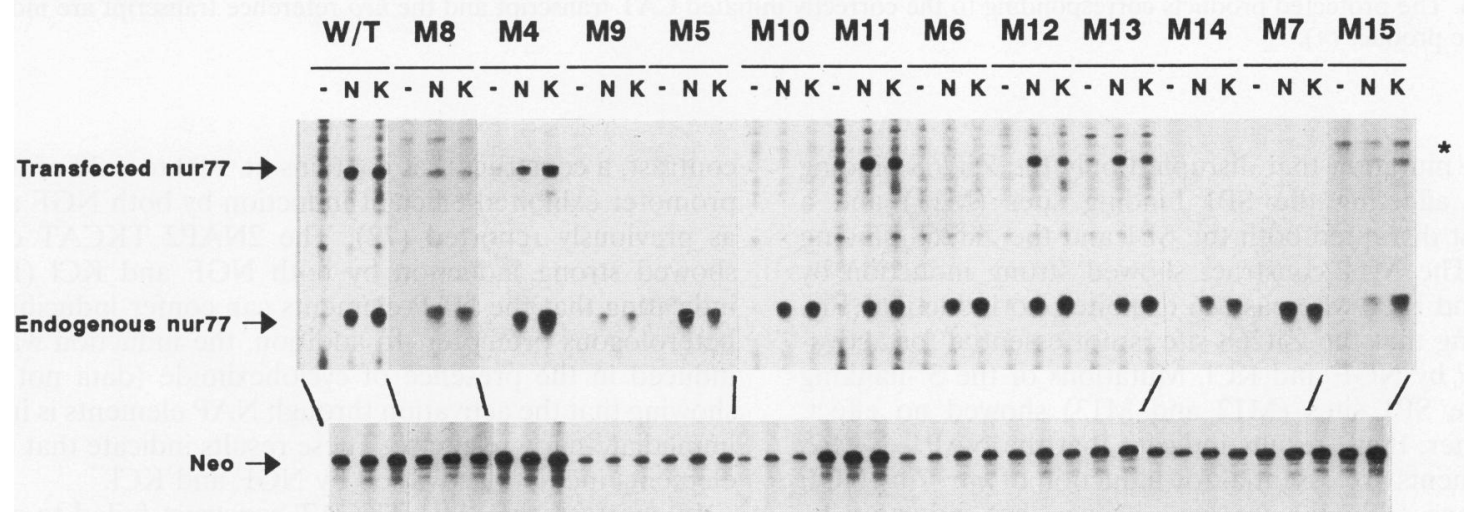

FIG. 3. Mutational analysis of the nur77 promoter. (A) Schematic illustration of the structure of the nur 77 minigene and sequences of the nur 77 promoter and mutants analyzed. Each mutant plasmid is identical to the 126/77TR minigene except for the nucleotide changes shown. The abilities of the mutant promoters to mediate induction by $\mathrm{NGF}$ and $\mathrm{KCl}$ are summarized. (B) S1 nuclease protection analysis of the nur77 promoter mutants. Cells were transfected with 126/77TR or mutant minigenes and analyzed as described for Fig. 2. RNA samples were isolated from transfected cells which were either unstimulated $(-)$ or stimulated with $\mathrm{NGF}(\mathrm{N})$ or $\mathrm{KCl}(\mathrm{K})$ for $1 \mathrm{~h}$. A nonspecific S1 protection product $(*)$ is indicated. W/T, wild type.

nuclease protection analysis of the minigene-derived transcripts following transient transfection into PC12 cells. Among the mutations tested, those that disrupted either one of the NAP sequences (M9, M5, M14, and M7) completely abolished activation by NGF or $\mathrm{KCl}$ (Fig. 3B). Thus, both NAP1 (nt -70 to -64$)$ and NAP2 (nt -41 to -35 ) appear necessary for induction by NGF and $\mathrm{KCl}$. The NAP1 and NAP2 elements share a sequence, $5^{\prime}$-TGCGTCA, even though their $5^{\prime}-$ and $3^{\prime}$-flanking sequences are different. Mutations of the 5'-flanking sequences of both NAP1 and NAP2 (M4 and M13) or the 3'-flanking sequence of NAP2 (M15) did not have any effect, whereas mutation of the 3 '-flanking sequence of NAP1 (M10) abolished nur77 induction by either NGF or $\mathrm{KCl}$.

The GC-rich region between the two NAP sites contains two overlapping SP1 sites as well as a Zif268 binding site. To distinguish which of these elements are required for induction, 

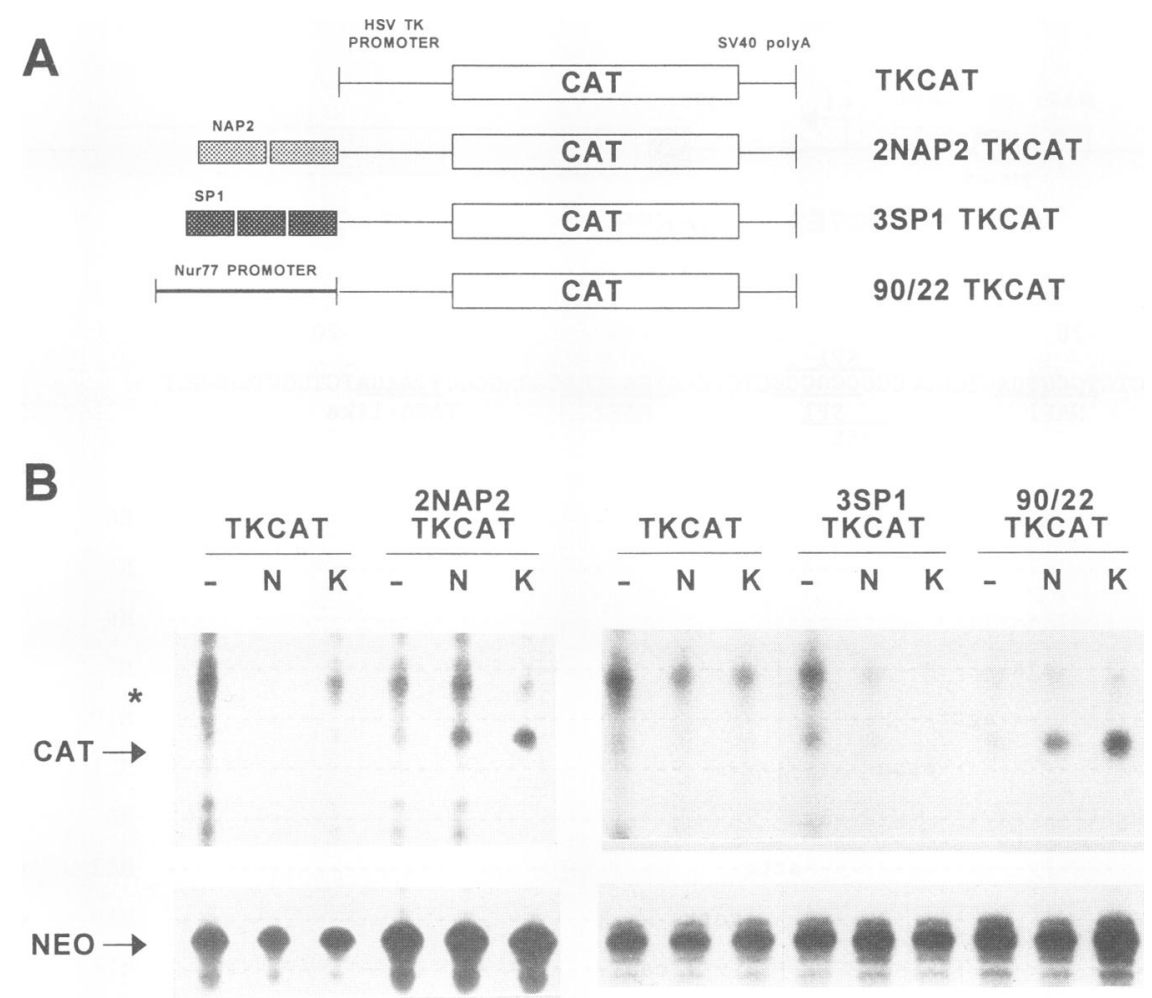

FIG. 4. NAP elements confer inducibility on a heterologous promoter. (A) Structure of TKCAT fusion gene constructs. Either two copies of synthetic NAP2 oligonucleotides (2NAP2 TKCAT), three copies of SP1 oligonucleotides (3SP1 TKCAT), or the nur77 promoter fragment spanning nt -90 to -22 (90/22 TKCAT) was inserted in front of the herpes simplex virus thymidine kinase (HSV TK) basal promoter linked to the CAT gene coding sequence. (B) S1 nuclease protection analysis of TKCAT fusion genes. A 26- $\mu \mathrm{g}$ amount of each TKCAT fusion gene plasmid and $14 \mu \mathrm{g}$ of pSV40neo reference plasmid were transfected into PC12 cells. Transfected cells were either not stimulated (-) or stimulated with NGF $(\mathrm{N})$ or $\mathrm{KCl}(\mathrm{K})$ for $1 \mathrm{~h}$, and expression of the fusion genes was analyzed by S1 nuclease protection assay of the CAT message as described elsewhere (72). The protected products corresponding to the correctly initiated CAT transcript and the neo reference transcript are indicated, as is a nonspecific product $(*)$.

we created a mutation that disrupted only the Zif268 binding site without affecting the SP1 binding sites (M11) and a mutation that disrupted both the SP1 and the Zif268 binding sites (M6). The M11 construct showed strong induction by both NGF and $\mathrm{KCl}$, whereas M6 exhibited no induction (Fig. 3B), indicating that the Zif268 site is not essential for activation of nur77 by NGF and $\mathrm{KCl}$. Mutations of the 3 '-flanking region of the SP1 sites (M12 and M13) showed no effect. Taken together, these results indicate that the NAP1, NAP2, and SP1 elements are essential for induction of nur77 by NGF and $\mathrm{KCl}$. Thus, although we have shown that induction by NGF and $\mathrm{KCl}$ is mediated through distinct signalling pathways (Fig. 1), the sequence requirements for induction by these agents appear to be indistinguishable.

To further evaluate the roles of the NAP elements and SP1 sites in nur77 activation, we examined their ability to confer inducibility on a heterologous promoter. We tested two specific constructs, one containing two copies of a region bearing the NAP2 element (nt -48 to -28 ) of the nur77 promoter (2NAP2 TKCAT; Fig. 4A) and the other containing three copies of the SP1 site (3SP1 TKCAT; Fig. 4A) cloned upstream of the thymidine kinase promoter driving expression of the chloramphenicol acetyltransferase (CAT) gene. Following transient transfection, the CAT transcript was detected by $\mathrm{S} 1$ nuclease protection assay (Fig. 4B). The parental vector, TKCAT, which contains the thymidine kinase basal promoter, showed no induction whatever by either $\mathrm{NGF}$ or $\mathrm{KCl}$. In contrast, a construct that contains nt -90 to -22 of the nur77 promoter exhibited efficient induction by both $\mathrm{NGF}$ and $\mathrm{KCl}$, as previously reported (72). The 2NAP2 TKCAT construct showed strong induction by both $\mathrm{NGF}$ and $\mathrm{KCl}$ (Fig. 4B), indicating that the NAP elements can confer inducibility on a heterologous promoter. In addition, the induction was superinduced in the presence of cycloheximide (data not shown), showing that the activation through NAP elements is indeed an immediate-early response. These results indicate that the NAP elements mediate activation by $\mathrm{NGF}$ and $\mathrm{KCl}$.

In contrast, the 3SP1 TKCAT construct failed to show any induction by either NGF or $\mathrm{KCl}$ (Fig. 4B). Since the SP1 site is required in the context of the nur77 minigene (Fig. 3) but itself cannot function as an inducible element, we interpret these data to indicate that the SP1 element acts as an essential element for nur77 promoter function rather than an inducible element. In the context of the thymidine kinase basal promoter, which contains SP1 sites, the NAP elements can function to confer inducibility.

JunD is a component of NAP element binding activity in PC12 cell nuclear extracts. To identify which proteins are bound to the NAP elements, an EMSA was employed to detect NAP element binding activity in PC12 cell nuclear lysates with ${ }^{32} \mathrm{P}$-labeled NAP2 synthetic oligonucleotides used as probes. In nuclear extracts of cells stimulated with NGF for $20 \mathrm{~min}$, we detected specific NAP binding activity (Fig. 5). This binding was abolished by the presence of excess cold NAP1 or cold 


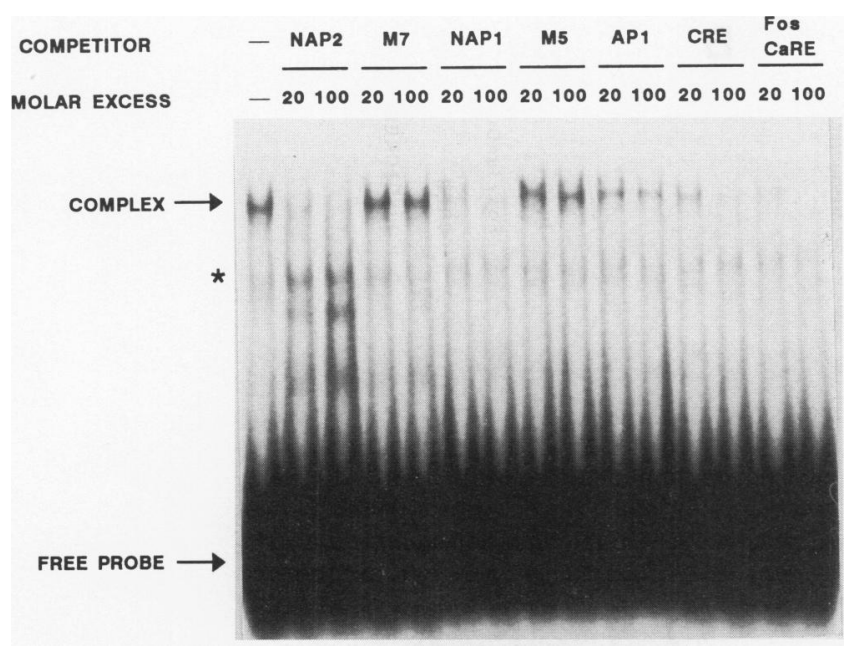

FIG. 5. NAP element binding activity in PC12 cell nuclear extracts. Nuclear extracts $(20 \mu \mathrm{g})$ from PC12 cells stimulated with NGF for 20 min were incubated with ${ }^{32} \mathrm{P}$-labeled, double-stranded NAP2 oligonucleotides either in the absence $(-)$ or presence of 20 - or 100 -fold excesses of the indicated unlabeled oligonucleotides as competitors. The DNA-protein complexes were detected as slowly migrating bands relative to the free probe in an EMSA. A nonspecific complex (*) is indicated.

NAP2 oligonucleotides, suggesting that the same binding proteins are likely to interact with both NAP1 and NAP2 elements. In contrast, the mutant oligonucleotides (M5 and M7) which contain mutations that abolished promoter activity were unable to compete with the NAP binding activity (Fig. 5). This result indicates that the NAP-binding proteins may include the transactivator of nur77. In addition, NAP binding activity was efficiently inhibited by oligonucleotides containing the CRE (TGACGTCA) or c-fos CRE/CaRE (TGACGTTT) and, to a lesser extent, by an AP1 (TGACTCA) oligonucleotide. This result suggests that members of either the CREB or the AP1 family of proteins may be components of the NAP binding activity. Similar results were obtained with nuclear extracts from either unstimulated cells or $\mathrm{KCl}$-stimulated cells (data not shown). These results are consistent with the idea that protein synthesis is not required for the activation of immediate-early genes and that preexisting factors are responsible for activation.

To further investigate the involvement of CREB or AP1 transcription factors in NAP binding, we applied antibodies specific to CREB or to Fos/Jun family members in NAP binding reaction mixtures for the EMSA (Fig. 6A). Among the antibodies tested, only anti-JunD antiserum was able to supershift the NAP element-protein complex, detected as a band with a slower electrophoretic mobility (complex II). Neither preimmune serum nor antibodies specific for CREB or any other Fos/Jun family members tested were able to supershift the NAP-protein complex. Since the same CREB or Fos/Jun antibodies are able to form supershifted complexes against their cognate in vitro-synthesized protein bound to DNA, this observation is not due to the inability of the antibodies to form a supershift complex in this assay (Fig. 6B). Thus, among the proteins tested, JunD can be identified as a component of the NAP binding activity in PC12 cell nuclear extracts, whereas CREB, thought to be involved in the activation of c-fos by both NGF and membrane depolarization $(17,54,55)$, does not appear to be a component of the NAP binding complex.

To investigate the binding of JunD to the NAP elements further, in vitro-transcribed and -translated JunD was used in reaction mixtures for binding to the NAP2 oligonucleotide for the EMSA (Fig. 7). While JunD alone failed to interact efficiently with either NAP1 or NAP2, it could bind effectively to both NAP1 and NAP2 in the presence of c-Fos. This result shows that bona fide JunD synthesized in vitro is able to bind the NAP elements in a heterodimeric form. However, since c-fos is not expressed in unstimulated PC12 cells (3), JunD is not likely to act through interaction with c-Fos. CREB synthesized in vitro was unable to form a complex with NAP1 or NAP2, either alone or in the presence of JunD. From these results and the results from the antibody supershift experiment (Fig. 6), we conclude that JunD is a component of NAP
A

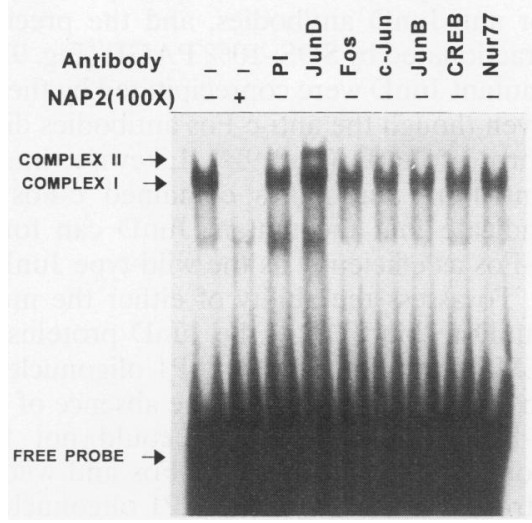

B

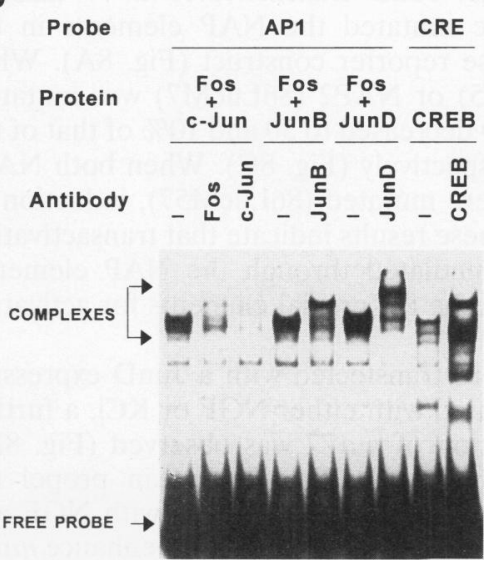

FIG. 6. JunD is a component of NAP element binding activity. (A) Antibody supershift analysis of NAP element binding activity. Nuclear extracts $(20 \mu \mathrm{g})$ from PC12 cells stimulated with NGF for 15 min were incubated with $2 \mu \mathrm{l}$ of preimmune serum (PI), $2 \mu \mathrm{l}$ of anti-JunD serum (JunD), or $5 \mu \mathrm{l}$ of antibodies specific for c-Fos, c-Jun, JunB, CREB, or Nur77 prior to the addition of the labeled NAP2 oligonucleotides. A 100 -fold molar excess of unlabeled NAP2 double-stranded oligonucleotides was included in one instance (+). (B) Antibody supershift of proteins synthesized in vitro. ${ }^{32} \mathrm{P}$-labeled AP1 or CRE oligonucleotides were incubated with in vitro-synthesized Fos/Jun complex or CREB as indicated. The same amounts of antibodies used in the experiment whose results are shown in panel A were added to the binding reaction mixtures. 


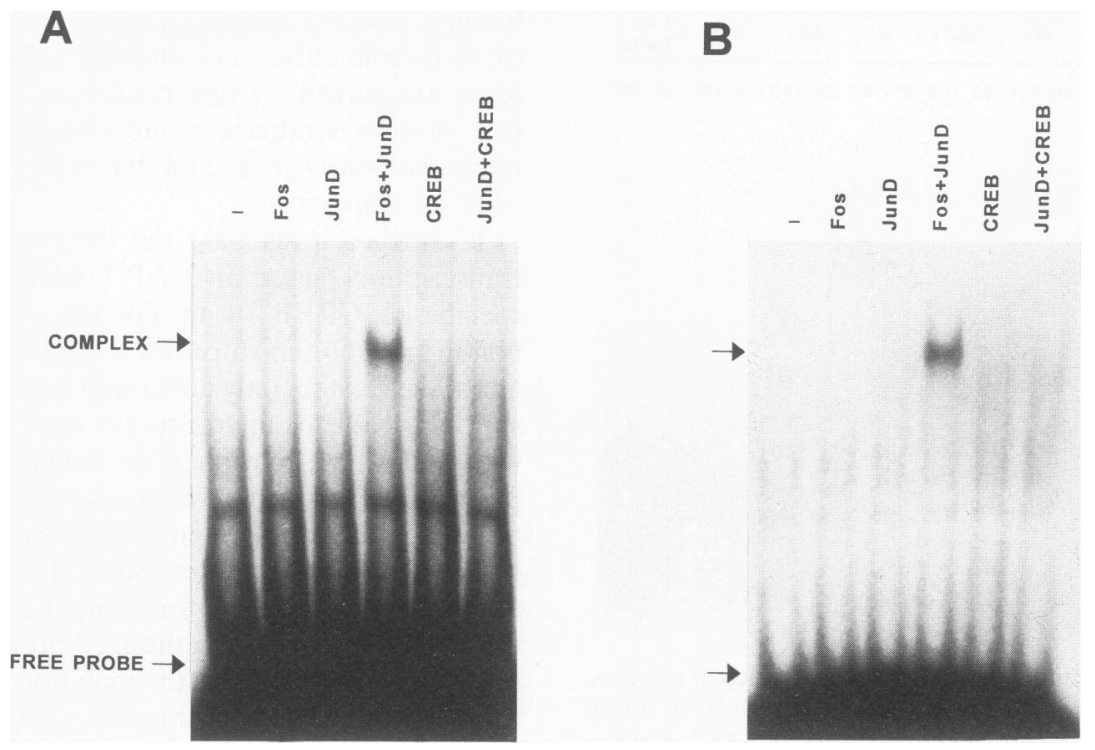

FIG. 7. Specificity of binding of JunD to NAP elements. Proteins were obtained by in vitro translation in rabbit reticulocyte lysates programmed with either c-fos, junD, or $C R E B$ RNA. A 2.5- $\mu$ l sample of each reaction mixture was used in an EMSA in the presence of either the labeled NAP1 (A) or NAP2 (B) double-stranded oligonucleotides in various combinations as indicated. The total volume of reticulocyte lysates was adjusted to $5 \mu \mathrm{l}$.

element binding activity and may play a role in the activation of nur77.

JunD transactivates nur77. Since JunD was recognized as being involved in NAP binding, we tested its ability to transactivate nur77. For this purpose, we constructed a reporter gene by fusing the nur 77 promoter region $(n t-86$ to +122$)$ to the luciferase coding sequence (Fig. 8A). The nur 77 promoter activity could be detected as luciferase activity. In cotransfection experiments with vectors that express proteins of the Fos/Jun family, only expression of JunD was able to transactivate the nur 77 promoter (about 40 -fold; Fig. 8B). In contrast, expression of either c-Fos, c-Jun, or JunB was unable to transactivate nur77 (Fig. 8B). Thus, JunD protein is unique among members of the Fos/Jun family in its ability to transactivate nur77.

To determine whether JunD transactivates nur77 through the NAP elements, we mutated the NAP elements in the context of the luciferase reporter construct (Fig. 8A). When either NAP1 (86LucM5) or NAP2 (86LucM7) was mutated, transactivation by JunD decreased to 30 and $10 \%$ of that of the wild-type promoter, respectively (Fig. 8C). When both NAP1 and NAP2 elements were mutated (86LucM57), induction by JunD was abolished. These results indicate that transactivation of nur77 by JunD is mediated through the NAP elements, which we have shown to be the crucial elements for activation by $\mathrm{NGF}$ and $\mathrm{KCl}$.

When PC12 cells were transfected with a JunD expression vector and then stimulated with either $\mathrm{NGF}$ or $\mathrm{KCl}$, a further increase in transactivation of nur77 was observed (Fig. 8D). Thus, while a high level of JunD protein can propel the transcription of nur77, stimulation of the cell with NGF and $\mathrm{KCl}$ can activate signalling pathways that act to enhance nur77 expression, possibly by modification of JunD or proteins that interact with JunD.

A JunD dominant-negative mutant blocks nur77 activation by NGF and KCl. To investigate the role of JunD in nur77 activation more directly, we developed a dominant-negative mutant of JunD to block the activities of the wild-type JunD protein. Since dominant-negative mutants of c-Fos and c-Jun have been successfully created by deleting their DNA binding domains $(43,45)$, we adopted a similar strategy (Fig. 9A). The JunD mutant, which has its DNA binding domain deleted, should retain the capacity to form homodimers or heterodimers through the leucine zipper region but should be unable to bind DNA. Thus, we reasoned that it would be possible to block the function of wild-type, endogenous JunD by overexpressing such a JunD dominant-negative mutant in cells.

We first characterized the properties of the JunD mutant protein. Wild-type and mutant JunD proteins were generated by in vitro transcription-translation and labeled with $\left[{ }^{35} \mathrm{~S}\right] \mathrm{me}$ thionine (Fig. 9B). To test their abilities to form dimers, labeled wild-type or mutant JunD was mixed with similarly labeled c-Fos to allow dimerization. The resulting proteins were subjected to immunoprecipitation with either anti-c-Fos or anti-JunD antibodies, and the precipitated proteins were fractionated by SDS-10\% PAGE (Fig. 9B). Both wild-type and mutant JunD were coprecipitated by the anti-c-Fos antibodies, even though the anti-c-Fos antibodies did not recognize either form of JunD (Fig. 9B). Likewise, immunoprecipitates with anti-JunD antibodies contained c-Fos protein. These data indicate that the mutant JunD can form heterodimers with c-Fos as efficiently as the wild-type JunD.

To assess the ability of either the mutant or the wild-type JunD to bind DNA, the JunD proteins were subjected to an EMSA with ${ }^{32}$ P-labeled AP1 oligonucleotide used as a probe in either the presence or the absence of c-Fos (Fig. 9C). While c-Fos or JunD by itself could not form a DNA-protein complex, the mixture of c-Fos and wild-type JunD formed a strong complex with the AP1 oligonucleotide. In contrast, no DNA binding activity could be detected with the mutant JunD, even in the presence of c-Fos (Fig. 9C). Moreover, when the mutant JunD protein was included in a binding reaction mixture with the wild-type JunD, the DNA binding activity of the wild-type protein was abolished (Fig. 9D). Taken together, these results indicate that the mutant JunD retains its ability to 
A

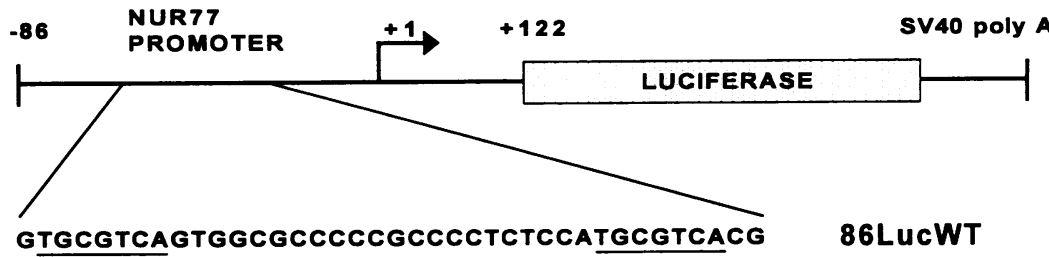

- - AGA - $\ldots \ldots \ldots$

86LucM5

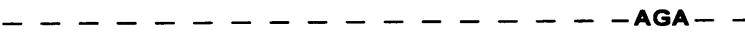

86LuCM7

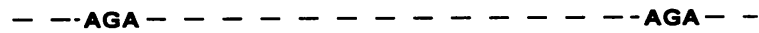

86 LucM57

B

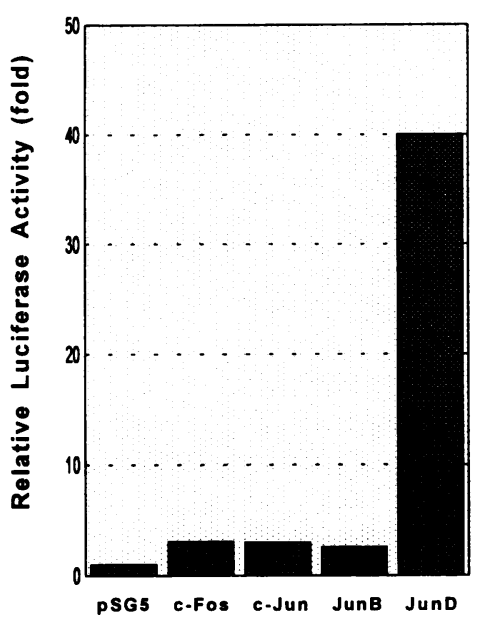

C

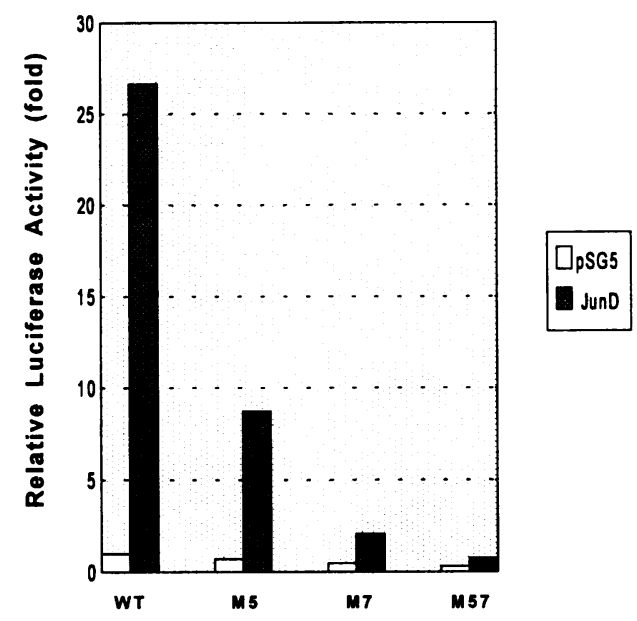

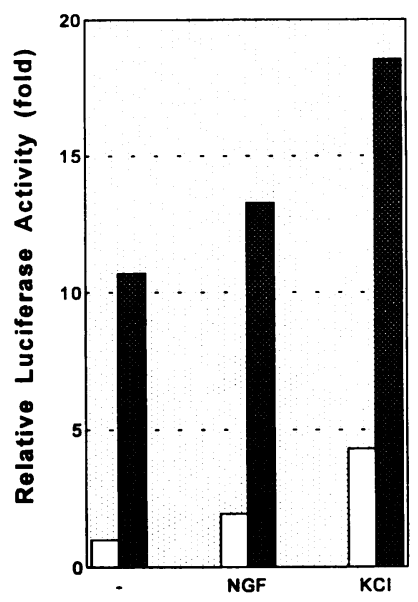

FIG. 8. Transactivation of $n u r 77$ by JunD. (A) Structure of nur77-luciferase fusion gene constructs. nt -86 to +122 of the nur 77 promoter were fused to the luciferase gene; base substitution mutations that ablated either the NAP1 (M5) or the NAP2 (M7) element or both (M57) are shown. (B) Transactivation of nur77 by JunD. PC12 cells were cotransfected with $2.5 \mu \mathrm{g}$ of nur77-luciferase fusion gene (86LucWT), $6 \mu \mathrm{g}$ of pPGK $\beta$-gal plasmid, and $20 \mu \mathrm{g}$ of plasmid expressing either c-Fos, c-Jun, JunB, or JunD. (C) JunD transactivates through NAP elements. PC12 cells were cotransfected with $20 \mu \mathrm{g}$ of pSGJunD, $6 \mu \mathrm{g}$ of pPGK $\beta$-gal, and $2.5 \mu \mathrm{g}$ of either wild-type nur77-luciferase fusion gene (86LucWT) or mutant constructs (86LucM5, 86 LucM7, or 86LucM57) as indicated. (D) Effects of NGF and KCl stimulation on transactivation by JunD. PC12 cells were cotransfected with $2.5 \mu \mathrm{g}$ of 86LucWT DNA, $6 \mu \mathrm{g}$ of pPGK $\beta$-gal plasmid, and $10 \mu \mathrm{g}$ of pSG5 or pSGJunD plasmid. Transfected cells were either not stimulated or stimulated with NGF or $\mathrm{KCl}$. Luciferase activities were normalized with $\beta$-galactosidase activities for transfection efficiencies. Results shown are the average of four independent experiments except for panel D (three independent experiments).

form heterodimers but cannot bind DNA and interferes with the DNA binding activities of the wild-type JunD in a dominant-negative fashion.

We next questioned whether this dominant-negative mutant JunD can block the induction of nur77 by NGF and $\mathrm{KCl}$. An expression construct with the mutant JunD coding sequence driven by the cytomegalovirus promoter was transiently cotransfected with the 126/77TR nur77 minigene into PC12 cells. As expected, transfected cells that were unstimulated did not show induction of nur77, whereas cells transfected with the parental vector showed strong induction of the endogenous and transfected nur77 upon stimulation by NGF or $\mathrm{KCl}$ (Fig. 10). However, when the mutant JunD expression vector was titrated into the transfection mixture, activation of the transfected nur77 by either NGF or $\mathrm{KCl}$ was inhibited in a dosedependent manner (Fig. 10). Since these transfections were carried out by electroporation under conditions in which most of the cells die, a large proportion of the surviving cells were transfected. Under these conditions, the induction of the endogenous gene was also affected by the overexpressed mutant JunD. The expression of a dominant-negative JunD protein is thus able to effectively block the induction of nur77 by NGF or KCl. Similar results were obtained when the nur77 promoter-luciferase construct was used as a reporter in place of the 126/77TR minigene (data not shown). From these results taken together, we conclude that JunD protein is indeed a transcription activator involved in the induction of nur77 by $\mathrm{NGF}$ or $\mathrm{KCl}$ in $\mathrm{PC} 12$ cells.

\section{DISCUSSION}

NGF and $\mathrm{KCl}$ activate nur77 through distinct but convergent signalling pathways. PC12 cells respond to NGF treatment and membrane depolarization with vastly different biological consequences $(21,22)$. Paradoxically, many of the same immediate-early genes are induced in both processes, suggest- 
A

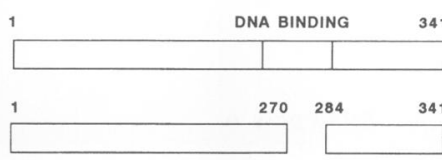

JunD

JunD mut

B

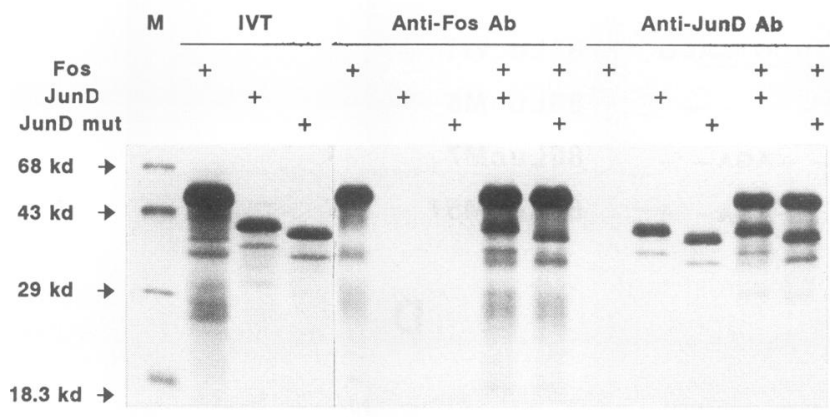

C

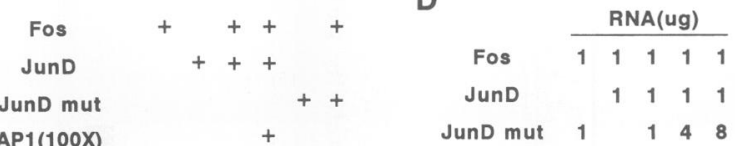

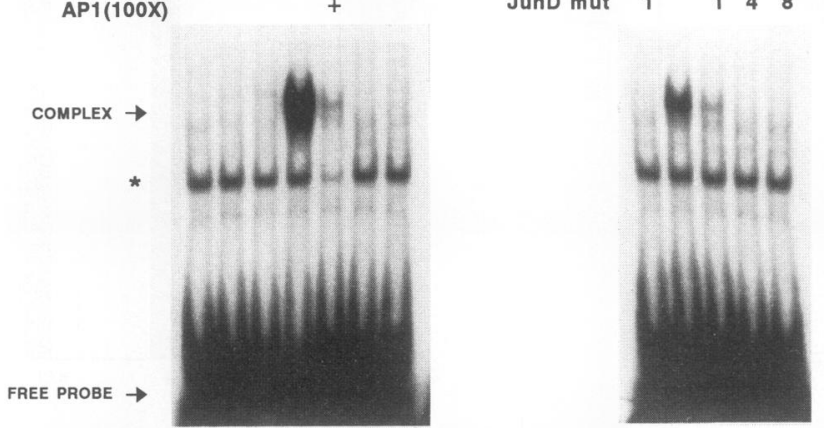

FIG. 9. Dominant-negative mutant of JunD. (A) Schematic diagram of wild-type and dominant-negative JunD. Amino acid residues 271 to 283 within the DNA binding domain were deleted in mutant JunD. (B) Dimerization of JunD mutant. c-Fos, JunD, and mutant JunD were translated in vitro in rabbit reticulocyte lysates in the presence of $\left[{ }^{35} \mathrm{~S}\right]$ methionine (lanes IVT). Reticulocyte lysates $(10 \mu \mathrm{l}$ each) containing c-Fos were mixed with lysates containing JunD or mutant JunD, and the dimerized proteins were immunoprecipitated with either anti-c-Fos or anti-JunD antibodies (Ab) as indicated. Proteins were visualized by fluorography after fractionation by SDS$10 \%$ PAGE. (C) Mutant JunD is unable to bind DNA. ${ }^{32} \mathrm{P}$-labeled AP1 oligonucleotides were incubated with $1 \mu l$ of in vitro translation reaction mixtures programmed either without or with c-fos, junD, or mutant junD RNA and analyzed by an EMSA to detect DNA binding. Unlabeled 100-fold molar excesses of AP1 oligonucleotides were included in one reaction [AP1(100X)]. The total volume of translation reaction mixture used in each case was adjusted with reticulocyte lysate to $2 \mu l$. (D) Mutant JunD inhibits DNA binding of wild-type JunD. In vitro translation reaction mixtures programmed with different amounts of c-fos, junD, and/or mutant junD RNA (indicated in micrograms) were incubated with labeled AP1 double-stranded oligonucleotides and subjected to an EMSA. The total RNA in the translation reaction mixture was adjusted to $10 \mu \mathrm{g}$ with irrelevant RNA.

ing that the immediate-early proteins synthesized under these conditions might have disparate activities through different combinatorial effects or posttranslational modifications (3). In this regard, it is interesting that Nur77 synthesized upon NGF or $\mathrm{KCl}$ treatment is differentially phosphorylated (25).

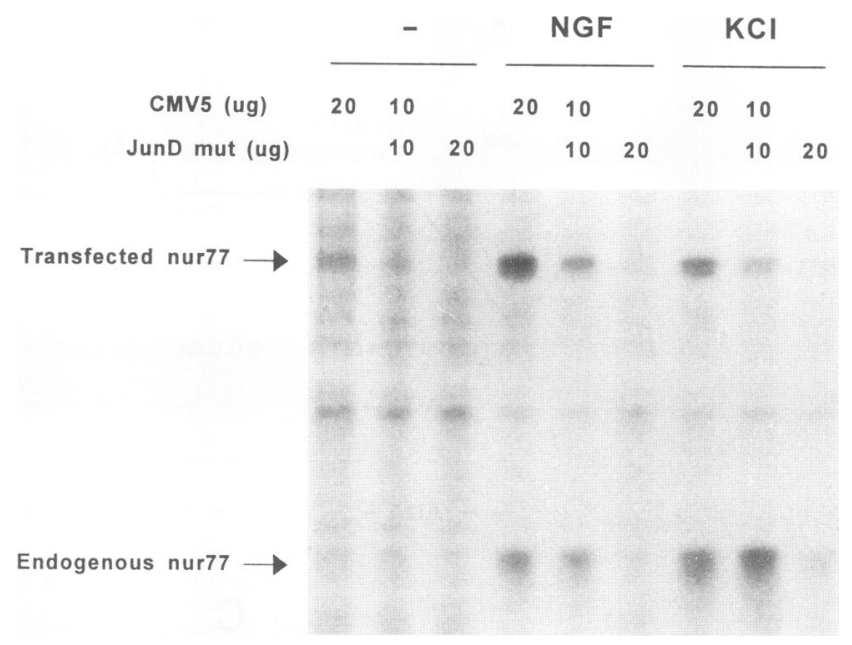

FIG. 10. Inhibition of nur77 induction by dominant-negative mutant of JunD. PC12 cells were cotransfected with $26 \mu \mathrm{g}$ of the nur77 126/77TR minigene, $6 \mu \mathrm{g}$ of pPGK $\beta$-gal, and either $20 \mu \mathrm{g}$ of the parental pCMV plasmid or 10 or $20 \mu \mathrm{g}$ of pCMVJunDmut expression plasmid (adjusted to a total of $20 \mu \mathrm{g}$ with the parental expression plasmid pCMV5) by electroporation. After transfection, cells were either unstimulated (-) or stimulated with $\mathrm{NGF}$ or $\mathrm{KCl}$ for $1 \mathrm{~h}$ as indicated. Expression of the transfected and the endogenous nur77 genes was analyzed by $\mathrm{S} 1$ nuclease protection assay. The RNA amount for $\mathrm{S} 1$ protection assay was normalized to the $\beta$-galactosidase activity of the extract, which serves as a control for transfection efficiencies.

That many of the same genes are induced by NGF and $\mathrm{KCl}$ treatment in PC12 cells suggests that these agents either work through different signalling pathways that act upon distinct regulatory sequences on the same genes or work through signalling pathways that converge upon the same transcription factors, which activate the identical genes. In the case of c-fos, the sequence elements necessary for $\mathrm{NGF}$ and $\mathrm{KCl}$ induction are separable: NGF induction requires the serum response element centered at nt $-310(53,63)$ as well as two CRE-like elements (17), and membrane depolarization requires a CRElike sequence centered at $n t-60(53,55)$. These data argue that $\mathrm{NGF}$ and $\mathrm{KCl}$ work through different signalling pathways that act upon distinct regulatory sequences to activate c-fos. In contrast, extensive promoter analysis presented in this study shows that two similar AP1-like sequences, NAP1 and NAP2, are necessary and sufficient to mediate induction by both NGF and $\mathrm{KCl}$ (Fig. 3 and 4). Thus, the sequence requirements for induction of nur77 by NGF and $\mathrm{KCl}$ appear indistinguishable.

Nevertheless, NGF and $\mathrm{KCl}$ clearly work through distinct signalling pathways to induce nur77, as they are differentially affected by specific kinase inhibitors (Fig. 1). Induction by NGF does not require phorbol ester-sensitive PKC- or CaMII kinase-dependent pathways (Fig. 1A and C) but is partially mediated through a PKA-dependent pathway (Fig. 1B). NGF binds to a cell surface receptor complex composed of a p $140^{\text {prototrk }}$ and a p $75^{\text {NGFR }}$ molecule $(27,30)$, resulting in the activation of an intrinsic receptor tyrosine kinase (31). Subsequent signalling events involve the activation of many kinases, including the MAP (mitogen-activated protein) kinases (24, $57,62,69)$. Thus, it is possible that MAP kinase-dependent pathways might contribute to the activation of nur77.

In contrast, membrane depolarization by elevated levels of extracellular $\mathrm{KCl}$ causes the influx of $\mathrm{Ca}^{2+}$ ions into the cells through voltage-dependent $\mathrm{Ca}^{2+}$ channels. Since the CaMII kinase inhibitor $\mathrm{KN}-62$ completely blocked $\mathrm{KCl}$-mediated 
nur77 induction, this result supports the idea that CaMII kinase is involved in this response (Fig. 1C). In addition, whereas PKC-dependent pathways are not involved in $\mathrm{KCl}$ induction of nur77 (Fig. 1A), PKA may be involved in nur77 activation (Fig. 1B). The activation of c-fos and zif268/NGFI-A by $\mathrm{KCl}$ has been shown to be attenuated in PKA-deficient PC12 cell lines (18). However, as neither membrane depolarization nor $\mathrm{Ca}^{2+}$ affects cAMP levels in PC12 cells (56), PKA may be activated by an alternate mechanism. It has been suggested that the intermediary step of $\mathrm{Ca}^{2+}$ signalling may participate in the activation of PKA without affecting cAMP levels in cells (1).

Although NGF- and $\mathrm{KCl}$-mediated activation of nur77 functions through distinct signalling pathways in PC12 cells, these pathways are likely to converge upon the same transcription factors, which act on the same sequence elements in the nur77 promoter. The NAP1 and NAP2 elements contain identical 7-bp sequences (5'-TGCGTCA) which are similar to the consensus AP1 binding site (5'-TGAGTCA) and the CRE (5'-TGACGTCA). The NAP elements can confer inducibility by both $\mathrm{NGF}$ and $\mathrm{KCl}$ on an otherwise unresponsive heterologous promoter (Fig. 4). This result suggests that the NAP element is a DNA sequence motif mediating the immediateearly response initiated by two distinct stimulatory agents, $\mathrm{NGF}$ and $\mathrm{KCl}$, in $\mathrm{PC} 12$ cells. In support of this idea, a sequence similar to that of NAP has been shown to be important in mediating zif268/NGFI- $A$ induction by NGF in PC12 cells (12). In addition, sequences similar to that of the NAP element have been identified in the c-fos and proenkephalin gene promoters as a functional CRE in PC12 cells and in C6 glioma cells, respectively $(32,61)$.

JunD regulates nur77 transcription. Several lines of evidence demonstrate that JunD is one of the key transcription factors involved in the activation of nur77 upon $\mathrm{NGF}$ or $\mathrm{KCl}$ stimulation. First, JunD, but not CREB or other members of the AP1 (Fos/Jun) family, is a component of the proteins in nuclear extracts that binds to the NAP element, which mediates transcriptional activation by $\mathrm{NGF}$ and $\mathrm{KCl}$ (Fig. 6). Second, JunD, but not other proteins of the AP1 family, can transactivate nur 77 specifically through the crucial NAP elements (Fig. 8). Third, a dominant-negative mutant of JunD effectively blocks activation of nur77 by $\mathrm{NGF}$ or $\mathrm{KCl}$ (Fig. 10).

The above findings are significant when interpreted in the context of immediate-early gene activation. Since activation occurs in the absence of new protein synthesis, we anticipate that preexisting transcription factors are responsible. JunD, initially identified on the basis of sequence homology with c-Jun (49), is constitutively expressed in many cell types (49). JunD can bind to AP1 elements (or the TPA response element [TRE]) or related sequences as a homodimer or as heterodimers with other members of the Fos and Jun families and regulate transcription $(33,34,42,46,50)$. In the unstimulated PC12 cell, c-jun, junB, and c-fos are not expressed (3). Thus, it is not surprising that the proteins encoded by these genes are not components of the NAP binding activity in nuclear extracts. It is also gratifying that JunD, but not other Fos/Jun proteins, can transactivate nur77. These results point to a unique specificity in the ability of JunD to transactivate nur77, and not all Fos/Jun proteins have this activity. Furthermore, the facts that other members of the fos/jun gene family are not expressed at the time of stimulation and can transactivate nur77 lend credence to the dominant-negative experiment. Since the dominant-negative JunD retains the ability to form dimers, the absence of other Fos/Jun proteins allows us to conclude that the dominant-negative mutant blocks JunD action and not that of other members of the Fos/Jun family.
Since CREB is known to be involved in the activation of c-fos by both NGF and membrane depolarization in PC12 cells $(17,56)$, and since a CRE oligonucleotide competes with the NAP element for binding to nuclear proteins (Fig. 5), we have considered the possible involvement of CREB in the activation of nur77. However, CREB is not a component of the NAP element binding activity in PC12 cell nuclear extracts, and in vitro-translated CREB does not bind to the NAP element. Since JunD is unlikely to act by itself to transactivate nur 77 (Fig. 6B), and since a CRE oligonucleotide competes with the NAP element for nuclear protein binding (Fig. 5), it is possible that another member of the CREB family of proteins might participate in nur77 activation. The ability of JunD to heterodimerize with CREB or CREM bZIP family members is consistent with this possibility $(23,39)$.

Distinct regulation of nur77 transcription. We now have sufficient information concerning the transcriptional activation of nur77 to recognize that distinct sequences regulate its induction in different cell types. In fibroblasts, the rapid and transient activation of nur 77 induced by serum growth factors is actually the superimposition of two distinct transcriptional responses: an immediate-early response which is independent of new protein synthesis and a delayed-early response which is dependent on new protein synthesis (66). The cis-acting sequence elements required for immediate-early activation of the gene were localized to a region of the promoter spanning nt -126 to $-87(66)$. This region contains a CArG-like element and the adjacent Ets binding site; both are required for significant induction (66). In contrast, delayed-early expression of nur77 in fibroblasts is mediated through nt -86 to -26 in the promoter, which correspond to the NAP elements and SP1 and Zif268 sites identified in this study as being responsible for the immediate-early activation in PC12 cells (66). Thus, sequence elements that mediate the immediate-early response in one cell type can mediate the delayed-early response in another. In contrast to the findings for fibroblasts and PC12 cells, the promoter region responsible for the nur77 activation by adrenocorticotrophic hormone in the adrenal cortical cell line Y-1 was localized further upstream (11). In T lymphocytes, activation of nur77 by TPA requires sequences between $\mathrm{nt}-378$ and -332 , whereas activation by apoptotic signals delivered through the $\mathrm{T}$-cell receptor requires sequences between nt -332 and -151 (37). Taken together, these findings point to a multiplicity of regulatory mechanisms that control the transcription of nur77 in different cell types.

\section{ACKNOWLEDGMENTS}

We are grateful to R. Bravo, R. Costa, and M. R. Montminy for providing valuable materials. We also thank $C$. Yeung and members of the laboratory for critical reading of the manuscript and S. Brodjian for technical assistance.

This work was supported by NIH grant R01 CA52220. L.F.L. is an Established Investigator of the American Heart Association.

\section{REFERENCES}

1. Aszodi, A., U. Muller, P. Friedrich, and H. C. Spatz. 1991. Signal convergence on protein kinase $\mathrm{A}$ as a molecular correlate of learning. Proc. Natl. Acad. Sci. USA 88:5832-5836.

2. Bading, H., D. D. Ginty, and M. E. Greenberg. 1993. Regulation of gene expression in hippocampal neurons by distinct calcium signaling pathways. Science 260:181-186.

3. Bartel, D. P., M. Sheng, L. F. Lau, and M. E. Greenberg. 1989. Growth factors and membrane depolarization activate distinct programs of early response gene expression: dissociation of fos and jun induction. Genes Dev. 3:304-313.

4. Chijiwa, T., A. Mishima, M. Hagiwara, M. Sano, K. Hayashi, T. Inoue, K. Naito, T. Toshioka, and H. Hidaka. 1990. Inhibition of 
forskolin-induced neurite outgrowth and protein phosphorylation by a newly synthesized selective inhibitor of cyclic AMP-dependent protein kinase, $\mathrm{N}$-[2-(p-bromocinnamylamino)ethyl]-5-isoquinolinesulfonamide (H-89), of PC12D pheochromocytoma cells. J. Biol. Chem. 265:5267-5272.

5. Christy, B., and D. Nathans. 1989. DNA binding site of the growth factor-inducible protein Zif268. Proc. Natl. Acad. Sci. USA 86: 8737-8741.

6. Cowan, N. J., P. R. Dobner, E. V. Fuchs, and D. W. Cleveland. 1983. Expression of human alpha-tubulin genes: interspecies conservation of 3' untranslated regions. Mol. Cell. Biol. 3:1738-1745.

7. Dalton, S., and R. Treisman. 1992. Characterization of SAP-1, a protein recruited by serum response factor to the c-fos serum response element. Cell 68:597-612.

8. Dash, P. K., K. A. Karl, M. A. Colicos, R. Prywes, and E. R. Kandel. 1991. cAMP response element-binding protein is activated by $\mathrm{Ca}^{2+} /$ calmodulin as well as cAMP-dependent protein kinase. Proc. Natl. Acad. Sci. USA 88:5061-5065.

9. Davis, I. J., T. G. Hazel, R.-H. Chen, J. Blenis, and L. F. Lau. 1993. Functional domains and phosphorylation of the orphan receptor Nur77. Mol. Endocrinol. 7:953-964.

10. Davis, I. J., T. G. Hazel, and L. F. Lau. 1991. Transcriptional activation by Nur77, a growth factor-inducible member of the steroid hormone receptor superfamily. Mol. Endocrinol. 5:854859.

11. Davis, I. J., and L. F. Lau. 1994. Endocrine and neurogenic regulation of the orphan nuclear receptors Nur77 and Nurr-1 in the adrenal gland. Mol. Cell. Biol. 14:3469-3483.

12. DeFranco, C., D. H. Damon, M. Endoh, and J. A. Wagner. 1993. Nerve growth factor induces transcription of NGFIA through complex regulatory elements that are also sensitive to serum and phorbol 12-myristate 13-acetate. Mol. Endocrinol. 7:365-379.

13. Dichter, M. A., A. S. Tischler, and L. A. Greene. 1977. Nerve growth factor-induced increase in electrical excitability and acetylcholine sensitivity of a rat pheochromocytoma cell line. Nature (London) 268:501-504.

14. Fisch, T. M., R. Prywes, M. C. Simon, and R. G. Roeder. 1989. Multiple sequence elements in the c-fos promoter mediate induction by cAMP. Genes Dev. 3:198-211.

15. Fujita, K., P. Lazaroyici, and G. Guroff. 1989. Regulation of the differentiation of PC12 pheochromocytoma cells. Environ. Health Perspect. 80:127-142.

16. Gabellini, N., M. C. Minozzi, A. Leon, and R. Dal Toso. 1992. Nerve growth factor transcriptional control of c-fos promoter transfected in cultured spinal sensory neurons. J. Cell Biol. 118:131-138.

17. Ginty, D. D., A. Bonni, and M. E. Greenberg. 1994. Nerve growth factor activates a Ras-dependent protein kinase that stimulates c-fos transcription via phosphorylation of CREB. Cell 77:713725 .

18. Ginty, D. D., D. Glowacka, D. S. Bader, H. Hidaka, and J. A. Wagner. 1991. Induction of immediate early genes by $\mathrm{Ca}^{2+}$ influx requires cAMP-dependent protein kinase in PC12 cells. J. Biol. Chem. 266:17454-17458.

19. Gonzalez, G. A., and M. R. Montminy. 1989. Cyclic AMP stimulates somatostatin gene transcription by phosphorylation of CREB at serine 133. Cell 59:675-680.

20. Greenberg, M. E., E. B. Ziff, and L. A. Greene. 1986. Stimulation of neuronal acetylcholine receptors induces rapid gene transcription. Science 234:80-83.

21. Greene, L. A., and A. S. Tischler. 1976. Establishment of a noradrenergic clonal line of rat adrenal pheochromocytoma cells which respond to nerve growth factor. Proc. Natl. Acad. Sci. USA 73:2424-2428.

22. Greene, L. A., and A. S. Tischler. 1982. PC12 pheochromocytoma cultures in neurobiological research. Adv. Cell. Neurobiol. 3:373414.

23. Hai, T., and T. Curran. 1991. Cross-family dimerization of transcription factors Fos/Jun and ATF/CREB alters DNA binding specificity. Proc. Natl. Acad. Sci. USA 88:3720-3724.

24. Halegoua, S., R. C. Armstrong, and N. E. Kremer. 1991. Dissecting the mode of action of a neuronal growth factor. Curr. Top. Microbiol. Immunol. 165:119-176.
25. Hazel, T. G., R. Misra, I. J. Davis, M. E. Greenberg, and L. F. Lau. 1991. Nur77 is differently modified in PC12 cells upon membrane depolarization and growth factor treatment. Mol. Cell. Biol. 11:3239-3246.

26. Hazel, T. G., D. Nathans, and L. F. Lau. 1988. A gene inducible by serum growth factors encodes a member of the steroid and thyroid hormone receptor superfamily. Proc. Natl. Acad. Sci. USA 85: 8444-8448.

27. Hempstead, B. L., D. Martin Zanca, D. R. Kaplan, L. F. Parada, and M. V. Chao. 1991. High-affinity NGF binding requires coexpression of the trk proto-oncogene and the low-affinity NGF receptor. Nature (London) 350:678-683.

28. Herschman, H. R. 1991. Primary response genes induced by growth factors and tumor promoters. Annu. Rev. Biochem. 60: 281-319.

29. Hipskind, R. A., V. N. Rao, C. G. Mueller, E. S. Reddy, and A. Nordheim. 1991. Ets-related protein Elk-1 is homologous to the c-fos regulatory factor p62TCF. Nature (London) 354:531-534.

30. Kaplan, D. R., B. L. Hempstead, D. Martin Zanca, M. V. Chao, and L. F. Parada. 1991. The trk proto-oncogene product: a signal transducing receptor for nerve growth factor. Science 252:554 558.

31. Kaplan, D. R., D. Martin Zanca, and L. F. Parada. 1991. Tyrosine phosphorylation and tyrosine kinase activity of the trk protooncogene product induced by NGF. Nature (London) 350:158160.

32. Kobierski, L. A., H.-M. Chu, Y. Tan, and M. J. Comb. 1991 cAMP-dependent regulation of proenkephalin by JunD and JunB: positive and negative effects of AP-1 proteins. Proc. Natl. Acad. Sci. USA 88:10222-10226.

33. Kovary, K., and R. Bravo. 1991. Expression of different Jun and Fos proteins during the $\mathrm{G}_{0}$-to- $\mathrm{G}_{1}$ transition in mouse fibroblasts: in vitro and in vivo associations. Mol. Cell. Biol. 11:2451-2459.

34. Kovary, K., and R. Bravo. 1992. Existence of different Fos/Jun complexes during the $\mathrm{G}_{0}$-to- $\mathrm{G}_{1}$ transition and during exponential growth in mouse fibroblasts: differential role of Fos proteins. Mol. Cell. Biol. 12:5015-5023.

35. Kunkel, T. A., J. D. Roberts, and R. A. Zakour. 1987. Rapid and efficient site-specific mutagenesis without phenotypic selection. Methods Enzymol. 154:367-382.

36. Lau, L. F., and D. Nathans. 1991. Genes induced by serum growth factors, p. 257-293. In P. Cohen and J. G. Foulkes (ed.), Molecular aspects of cellular regulation, vol. 6. Hormonal regulation of transcription. Elsevier, Amsterdam.

37. Liu, Z.-G., S. W. Smith, K. A. McLaughlin, L. M. Schwartz, and B. A. Osborne. 1994. Apoptotic signals delivered through the T-cell receptor of a T-cell hybrid require the immediate-early gene nur-77. Nature (London) 367:281-284.

38. Marais, R., J. Wynne, and R. Treisman. 1993. The SRF accessory protein Elk-1 contains a growth factor-regulated transcriptional activation domain. Cell 73:381-393.

39. Masquilier, D., and P. Sassone Corsi. 1992. Transcriptional crosstalk: nuclear factors CREM and CREB bind to AP-1 sites and inhibit activation by Jun. J. Biol. Chem. 267:22460-22466.

40. Milbrandt, J. 1988. Nerve growth factor induces a gene homologous to the glucocorticoid receptor gene. Neuron 1:183-188.

41. Minty, A., and L. Kedes. 1986. Upstream regions of the human alpha cardiac actin gene that modulate its transcription in muscle cells: presence of an evolutionarily conserved repeated motif. Mol. Cell. Biol. 6:2125-2136.

42. Nakabeppu, Y., K. Ryder, and D. Nathans. 1988. DNA binding activities of three murine Jun proteins: stimulation by Fos. Cell 55:907-915.

43. Okuno, H., T. Suzuki, T. Yoshida, Y. Hashimoto, T. Curran, and H. Iba. 1991. Inhibition of jun transformation by a mutated fos gene: design of an anti-oncogene. Oncogene 6:1491-1497.

44. Parkes, D., S. Rivest, S. Lee, C. Rivier, and W. Vale. 1993. Corticotropin-releasing factor activates c-fos, NGFI-B, and corticotropin-releasing factor gene expression within the paraventricular nucleus of the rat hypothalamus. Mol. Endocrinol. 7:1357-1367.

45. Ransone, L. J., J. Visvader, P. Wamsley, and I. M. Verma. 1990 Trans-dominant negative mutants of Fos and Jun. Proc. Natl. Acad. Sci. USA 87:3806-3810. 
46. Risse, G., K. Jooss, M. Neuberg, H. J. Bruller, and R. Muller. 1989. Asymmetrical recognition of the palindromic AP1 binding site (TRE) by Fos protein complexes. EMBO. J. 8:3825-3832.

47. Rivera, V. M., and M. E. Greenberg. 1990. Growth factor-induced gene expression: the ups and downs of c-fos regulation. New Biol. 2:751-758.

48. Rodriguez-Pena, A., and E. Rozengurt. 1984. Disappearance of $\mathrm{Ca}^{2+}$-sensitive, phospholipid-dependent protein kinase activity in phorbol ester-treated 3T3 cells. Biochem. Biophys. Res. Commun. 120:1053-1059.

49. Ryder, K., A. Lanahan, E. Perez Albuerne, and D. Nathans. 1989. jun-D: a third member of the jun gene family. Proc. Natl. Acad. Sci. USA 86:1500-1503.

50. Ryseck, R. P., and R. Bravo. 1991. c-JUN, JUN B, and JUN D differ in their binding affinities to AP-1 and CRE consensus sequences: effect of FOS proteins. Oncogene 6:533-542.

51. Ryseck, R. P., H. MacDonald Bravo, M. G. Mattei, S. Ruppert, and R. Bravo. 1989. Structure, mapping and expression of a growth factor inducible gene encoding a putative nuclear hormonal binding receptor. EMBO. J. 8:3327-3335.

52. Sambrook, J., E. F. Fritsch, and T. Maniatis. 1989. Molecular cloning: a laboratory manual, 2nd ed. Cold Spring Harbor Laboratory Press, Cold Spring Harbor, N.Y.

53. Sheng, M., S. T. Dougan, G. McFadden, and M. E. Greenberg. 1988. Calcium and growth factor pathways of c-fos transcriptional activation require distinct upstream regulatory sequences. Mol. Cell. Biol. 8:2787-2796.

54. Sheng, M., and M. E. Greenberg. 1990. The regulation and function of c-fos and other immediate early genes in the nervous system. Neuron 4:477-485.

55. Sheng, M., G. McFadden, and M. E. Greenberg. 1990. Membrane depolarization and calcium induce c-fos transcription via phosphorylation of transcription factor CREB. Neuron 4:571-582.

56. Sheng, M., M. A. Thompson, and M. E. Greenberg. 1991. CREB: a $\mathrm{Ca}(2+)$-regulated transcription factor phosphorylated by calmodulin-dependent kinases. Science 252:1427-1430.

57. Thomas, S. M., M. DeMarco, G. D'Arcangelo, S. Halegoua, and J. S. Brugge. 1992. Ras is essential for nerve growth factor- and phorbol ester-induced tyrosine phosphorylation of MAP kinases. Cell 68:1031-1040.

58. Tokumitsu, H., T. Chijiwa, M. Hagiwara, A. Mizutani, M. Terasawa, and H. Hidaka. 1990. KN-62, 1-[N,O-bis(5-isoquinolinesulfonyl)-N-methyl-L-tyrosyl]-4-phenylpiperazine, a specific inhibitor of $\mathrm{Ca}^{2+} /$ calmodulin-dependent protein kinase II. J. Biol. Chem. 265:4315-4320.

59. Treisman, R. 1987. Identification and purification of a polypeptide that binds to the c-fos serum response element. EMBO J. 6:27112717.
60. Treisman, R. 1990. The SRE: a growth factor responsive transcriptional regulator. Semin. Cancer Biol. 1:47-58.

61. Velcich, A., and E. B. Ziff. 1990. Functional analysis of an isolated fos promoter element with AP-1 site homology reveals cell typespecific transcriptional properties. Mol. Cell. Biol. 10:6273-6282.

62. Vetter, M. L., D. Martin Zanca, L. F. Parada, J. M. Bishop, and D. R. Kaplan. 1991. Nerve growth factor rapidly stimulates tyrosine phosphorylation of phospholipase C-gamma 1 by a kinase activity associated with the product of the trk protooncogene. Proc. Natl. Acad. Sci. USA 88:5650-5654.

63. Visvader, J., P. Sassone Corsi, and I. M. Verma. 1988. Two adjacent promoter elements mediate nerve growth factor activation of the c-fos gene and bind distinct nuclear complexes. Proc. Natl. Acad. Sci. USA 85:9474-9478.

64. Watson, M. A., and J. Milbrandt. 1989. The NGFI-B gene, a transcriptionally inducible member of the steroid receptor gene superfamily: genomic structure and expression in rat brain after seizure induction. Mol. Cell. Biol. 9:4213-4219.

65. Watson, M. A., and J. Milbrandt. 1990. Expression of the nerve growth factor-regulated NGFI-A and NGFI-B genes in the developing rat. Development 110:173-183.

66. Williams, G. T., and L. F. Lau. 1993. Serum induction of the growth factor-responsive nuclear receptor gene nur77: dissociation of immediate early and delayed early responses. Mol. Cell. Biol. 13:6124-6136.

67. Wilson, T. E., T. J. Fahrner, M. Johnston, and J. Milbrandt. 1991. Identification of the DNA binding site for NGFI-B by genetic selection in yeast. Science 252:1296-1300.

68. Wilson, T. E., A. R. Mouw, C. A. Weaver, J. Milbrandt, and K. L. Parker. 1993. The orphan nuclear receptor NGFI-B regulates expression of the gene encoding steroid 21-hydroxylase. Mol. Cell. Biol. 13:861-868.

69. Wood, K. W., C. Sarnecki, T. M. Roberts, and J. Blenis. 1992. ras mediates nerve growth factor receptor modulation of three signaltransducing protein kinases: MAP kinase, Raf-1, and RSK. Cell 68:1041-1050.

70. Woronicz, J. D., B. Calnan, V. U. Ngo, and A. Winoto. 1994. Requirement for the orphan steroid receptor Nur77 in apopotosis of T-cell hybridomas. Nature (London) 367:277-281.

71. Yamamoto, K. K., G. A. Gonzalez, W. H. Biggs III, and M. R. Montminy. 1988. Phosphorylation-induced binding and transcriptional efficacy of nuclear factor CREB. Nature (London) 334:494 498.

72. Yoon, J. K., and L. F. Lau. 1993. Transcriptional activation of the inducible nuclear receptor gene nur 77 by nerve growth factor and membrane depolarization in PC12 cells. J. Biol. Chem. 268:91489155 . 